\title{
Small and Medium Enterprises Growth and Competitiveness: The Importance of Marketing Strategies Role
}

\author{
Muazu Hassan Muazu ${ }^{1^{*}}$, Hauwa'u Hassan Nashehu², Ummi Rahma Shehu ${ }^{3}$ \\ ${ }^{1}$ Dangote Business School, \\ Bayero University Kano, Kano State, PMB 3011, NIGERIA \\ ${ }^{2}$ Department of Business Management, \\ Federal University Dutsinma, Katsina State, PMB500, NIGERIA \\ ${ }^{3}$ Department of Business Administration and Entrepreneurship, \\ Bayero University Kano, Kano State, PMB 3011, NIGERIA \\ *Corresponding Author
}

DOI: https://doi.org/10.30880/jstard.2021.03.02.001

Received 27 January 2021; Accepted 15 June 2021; Available online 15 December 2021

\begin{abstract}
The growing competition among businesses of small medium or large is an area of concern to business growth and competitiveness. Strategies have been used to differentiate the undertakings of various enterprises irrespective of industrial affiliation, specifically marketing strategies are used to reach the customers and tackle competition. The adoption and implementation of unsuitable marketing strategy exposes the weaknesses of small and medium enterprises (SMEs) and the challenges to capture sizable market share. This paper is aimed at examining the types of marketing strategies suitable for SMEs and how they affect their growth and competitiveness in developing countries. A review survey approach was employed in this work and related literature from journal articles, professional reports, term papers and dissertations were reviewed. It has been discovered that marketing strategies like relationship management, branding, product and pricing differentiation, market segmentation and channel cultivation are crucial for the sustainable growth and competitiveness of SMEs in developing countries. Some propositions were made on some unpopular marketing strategies that could be explored by SMEs for competitiveness and international markets.
\end{abstract}

Keywords: Marketing strategy, growth, competitiveness, SMEs, marketing practice

\section{Introduction}

Globalisation and technological advancement are pushing for the growing competition in the small and medium enterprises business ecosystem. The function of marketing is critical to the continued existence and growth of SMEs (Ogundele et al., 2013). Marketing strategies evolved and often serve as one of the tools that helps swing the direction of current marketing sensations along the business cycle for most categories of business and industries (Sheetal, Sangeeta $\&$ Kumar, 2012). The role of marketing strategy in the enterprise depends on the choice and formulation of strategies that help to choose the appropriate customer, build relationships of trust with them and exploit potentials for growth (Kariithi, 2015).

The role of SMEs in countries' economies around the globe is critical. It helps in creating employment and equally contributing to innovation in some societies (OECD, 2017). They account for more than 95\% of businesses, and offers $60 \%-70 \%$ of employment and generates a large share of new jobs in many economies (OECD, 2000). The importance of SMEs to economies is overwhelming, as it represents a vital part of the large-scale industries supply chain in the form of forward and backward connections to the overall industrial sector (Sheetal et al., 2012). SMEs produces and exploit local 
skills, creates employment in developing economies, boosts industrial growths and enhances the economic value chain in the developing nations. SMEs are significant to the determinations for the achievement of environmental sustainability and more inclusive growth (OECD, 2017). The dynamics of SMEs in the developing economies are different from what is obtained in advanced societies. Issues like poor infrastructure, information technology and lack of access to international markets affect the success of SMEs across the world (OECD, 2017). Most often than not, the challenges are more prevalent in developing economies.

The spontaneous nature of SMEs is based on precise situations and the implementation of marketing strategies without a pre-planning activity (Hill, 2001). Furthermore, Marcati et al. (2008) advocate that these actions are appraised based on the manager's perceptions of marketing schemes. Based on the foregoing, studies by Bettiol et al. (2012) revealed that marketing strategy in SMEs is solely driven by the manager and it is neither a product of a systematic search for opportunities nor a planned analysis of the relevant market. It means that the marketing effort is more of a reactionary process towards business environmental changes. Wiig (2004) opines that the business environment is in continuous development in terms of diversity and complexity and that for SMEs to thrive in the global competitive market they have to focus on flexibility and efficiency. Thus marketing strategy requires a clear understanding of how marketing works within a firm and its environment. According to Hammond (2001), businesses would have to stick to a certain marketing strategy and continue to improve it. Empirical research evidence on marketing in SMEs by Franco et al. (2014) further demonstrated the recognition of the importance of marketing activities, which also depend on the size of firms. As posited by Mokhtar (2013), SMEs size, availability, technology, financial constraints and poor marketing activities faced difficulties in maintaining the pace of development and growth.

Sound marketing activities is determined by a good re-counting of the sales force exertions for the firm's present performance and future growth in small businesses. The variance between sales and marketing orientation is elusive and occasionally difficult to notice (Izverciana, Micleaa \& Potraa, 2016). Thus, SMEs have to be conscious of the difference between successes generated by the occasional rise in sales efforts and the need to take advantage of emerging opportunities. It's understandable that without sells business organisations will not be able to sustain their operations. By the same token, without undertaking relevant marketing activities, strategies and planning for both short term (salesoriented), medium and long-term (meeting consumer needs and desires), SMEs might find it difficult to adapt to environmental changes in their various field of undertakings (Izverciana, Micleaa \& Potraa, 2016).

Marketing, like it has been a core interface between firms and their customer, so is marketing strategy supposed to be for SMEs. Earlier academic research has focused more on fortune companies in the development of marketing management theories (Tarassova, 2003). Topics related to marketing in SMEs tend to be ignored over the years, the few ones tend to look at the manual fundamentals for start-ups, competent advice or solutions on various operational activities (Tarassova, 2003). Other few scholars did some empirical studies on marketing strategies, behaviour and SMEs growth (Kariithi, 2015; Gajanayake, 2002; Trivedi, 2013), performance (Njanja, 2009; Magunga, 2010), competitive advantage (Obonyo, 2013) and marketing practices (Ogundele et al., 2013).

This article is therefore aimed at exploring the various positions on the role marketing strategy could play in the development, growth and competitiveness of SMEs in developing economies. It is with the view to bridge the gap in the field of SMEs marketing as pointed out by Tarassova, (2003), Kariithi (2015), OECD (2017) so as to expand literature and present solutions to the challenges of SMEs in terms of marketing strategies suitable for the various firms.

\section{Material and Method}

This article employed literature survey approach to put up materials used for the write-up. A literature survey method was the use of secondary source of information to evaluate the state of knowledge on a phenomenon. Specifically, a narrative and synthesis kinds of review were utilized in the current article. They were chosen to demonstrate and develop authors' familiarity with previous works on SMEs growth and competitiveness and how marketing strategies could explored as the subject matter of the article. We surveyed works from books, journals, theses and internet sources to integrate our positions on the subject matter. Empirical studies were reviewed to ascertain the trend of the relationships between marketing strategy and SMEs growth and competitiveness.

\section{Concept of Marketing Strategy}

Marketing strategy is that management undertaking that pays emphasis on a firm's mission searches for unique opportunities, determines whether they fit the organization's strategic direction, defines the measures for success, and continually reassesses opportunities (Gaynor, 2002). It is about finding ways to fit-in into new markets and reinventing the wheel into an existing market profitably. The term competitive marketing strategies refers to both radical and incremental changes in thinking, things, and processes or in services delivery by firms (McAdam \& McClelland, 2002). Marketing strategies are continuous processes that are diverse and unique exploits, which are obviously essential to be revised on yearly basis in order to accomplish predetermined goals by firms (Sheetal et al., 2012). They are planned activities that are dynamic I nature that follows the trend of the market situation.

The build-up of marketing strategies is in tandem with the product life cycle to manage market competition and competitors (Sheetal et al., 2012; Kariithi et al., 2015). Thus understanding the marketing mix connection with strategies 
particularly as regards product, which could be boosted by an intensification of product line depth and width that must be attuned to market demand (Kotler \& Keller, 2008). The issue of branding sufficed in venturing into any market. The drive for product innovation in tandem with the assertion of scholars like Kotler and Keller (2008) and Barbu et al. (2010) on the need for SMEs to be creative beyond the conventional naming of products or services. Other mix elements include price, place and promotion that must be put into consideration to achieve the benefits of marketing in the performance, growth and competitiveness of SMEs.

Effective price constitutes one of the major marketing mix strategies, as it drives a firm's profit, subsistence and growth pattern. Kotler and Keller (2008) maintain that to have a satisfactory estimation of the price is a masculine task because it is vastly dependent on the elasticity of demand and independent of demand and sales. What it means is that SMEs should establish product positioning and target markets before pricing of brand. On the other hand, O'Dwyer, Gilmore and Carson (2009) were of the view that customer awareness, profit margin, competitors pricing, market dynamics are determinants of effective pricing strategy.

Promotion is the communicator of a firm's offerings to its prospective customers. Current and potential customers get informed, reminded and persuaded through marketing promotion (Sheetal et al., 2012). Among the popular promotional mix, advertising, sales promotion, billboards, direct marketing and personal selling are commonly used by SMEs. However, a combination of all the mix element flourishes more but requires a huge budget, which might not be feasible for SMEs in developing countries.

\section{Small and Medium Enterprises}

The term Small and Medium Enterprises (SMEs) covers a wide range of definitions and measures, varying from country to country. Some of the commonly used criteria are the number of employees, total net assets, sales, and investment level. SMEs are also regarded as non-subsidiary, autonomous firms which employ less than a given amount of workforces (OECD, 2017). This amount varies across different national statistical systems. However, the most common definitional basis used is employment. Presently the SME Department of the World Bank considers the following definitions: Small Enterprises are defined to have up to 50 employees, with total assets and total sales of up to $\$ 3$ million while Medium Enterprise is one that has up to 300 employees, having total assets and total sales of up to $\$ 15$ million per annum (ILO, 2012).

In the European Union, SMEs must have an annual turnover of EUR 40 million or less and/or a balance-sheet valuation not exceeding EUR 27 million. The most common maximum size is 250 employees, as in the European Union (OECD, 2000). Nevertheless, some nation-states set the maximum limit at 200 employees, while in the US SMEs are considered to include firms with fewer than 500 employees. SMEs are regarded as those firms with fewer than 50 employees, while micro-enterprises have at most 10, or in some cases 5 workers (ILO, 2012; Hellberg, 2000). The definition used to describe the SME sector in many African countries are based on employment size and include both paid and unpaid workers (Kariithi, 2015). A micro-enterprise is defined as having no more than 10 employees; a small enterprise with 11-50 employees and a medium/large enterprise with more than 50 employees.

Most SME jobs are in the service sector, which now accounts for two-thirds of economic activity and employment in OECD countries (OECD, 2017). Smaller firms are found particularly in merchandise (wholesale \& retail) businesses, the hotel and restaurant venture, communications and business services, and building. SMEs also account for a high fraction of manufacturing firms in many developed and developing countries and provide in any case half of manufacturing employment (OECD, 2000). Smaller enterprises are increasingly found in technology-based businesses such as information and communications technology (ICT) and biotechnology.

SMEs prevail in the important strategic business services subsector, including services relating to computer software and information processing, research and development, marketing, business organisation and human resource development. Increased outsourcing by major manufacturing firms, combined with new technologies that have allowed SMEs to win market niches, has led to $10 \%$ annual growth in these knowledge-based services in recent years (OECD, 2017). The fact that the average firm size in strategic business services is a percentage of the regular size of firms in manufacturing or in the economy as a whole is an indication of the importance of SMEs in this field.

\subsection{SMEs Growth and Competitiveness}

Enterprise growth is one of the core issues in entrepreneurship, venture creation, innovation and SME (Delmar, 2006). Understanding the significance of SMEs in economic growth and employment creation in developing countries calls for the need to research their growth (Sarlija et al., 2016). By doing so it will usher the sector into new insights that will guide SME to meet up with global market dynamics and competition. It is important to note that the growth of an enterprise is not a game of luck rather is associated with certain attributes, strategies, behaviour and decisions of the firm (Delmar, 2006). These attributes may not be far from financial stand, assets, revenue and liabilities. However, the priority of this paper is SMEs growth itself and not its determinants. In this regard, the following paragraphs looked at certain measures used in defining enterprise growth.

Enterprise growth is multidimensional and it is viewed from various perspectives. Authors like Kiviluoto, Brannback and Carsrud (2011), Delmar (2006), and Davidsson, Steffens and Fitzsimmons (2009) considered an increase in sales 
revenue, number of workforce and assets as the common indices of enterprise growth. SMEs ability to positively bring about change in their sales revenue, employ more people and expand the number of their assets are considered growing. Sarlija et al. (2016) regarded growth from two methodological points of views, quantitatively (revenue, output and volume of transactions) and qualitatively (product quality and market position). It was further recommended that growth could be considered from rising in profit, expansion in productivity and market share (Sarlija et al., 2016). This recommendation was arrived at after empirical findings from a survey by the authors. At this juncture, it could be argued that when all the varying measures of growth are put together could explain a great deal of what SMEs growth is all about. Therefore, SMEs growth is explained as any positive change in sales revenue, market share, profit, productivity, employee's size and assets of the firm.

Competitiveness might wide and vast to use a single dimension to explain. Competitiveness is the ability of a firm to produce goods and services that match the market demands or needs (Putnik \& Cruz-Cunha, 2008). It is a normal phenomenon to compete with business rivals in the market place. Firm competitiveness is the ability to sustainably accomplish its multiple functions of satisfying the needs of customers and making a profit (Vlachevi, Notta $\&$ Tsounis, 2017; Nelson, 1996). This ability could be built by offering customers value for their patronage than what is obtainable elsewhere. "Competitiveness determines the ability to conquer new markets, to outplay other actors in the market, to attract investment and to grow" (Falciola, Jansen \& Rollo, 2020, pg.1). The dynamism of competitiveness lies in the focus of different perspectives. Some viewed it from a one-stand point where conquering market today is all it matters, others considered it from continuous conquering while some combined it with following the market trend. Thus, in the current article, we viewed competitiveness from both sides, winning today, tomorrow and the future that suit the changing market situation.

A fourth element was introduced in the explanation of firm competitiveness. At initial review currency win, sustainable win and adjusting to market changes were at best in explaining the competitiveness of a firm. Falciola et al. (2020) introduced another element as 'connect', according to them the element highlights the significance to connect efficiently to information channels to steer a competitive atmosphere. Businesses must therefore be innovative, continue to upgrade their delivery services to adapt to market fluctuations and improve quality by escalating its market share at the detriment of poor-performing firms (Putnik \& Cruz-Cunha, 2008).

\section{Marketing Strategy for SMEs}

The marketing strategy may seem to be a work more applicable to larger organizations than smaller enterprises. However, small business is similarly influenced by their marketing strategy choices. According to Kariithi (2015), SMEs marketing strategies are characteristically those strategies and operational process choices made by enterprise owners to ensure superior performance and competitiveness of their business. The general perception might be that the usual small business is more productive, whilst larger organizations are more diligent in their marketing strategies process (Sarlija et al., 2016). In this article, the authors argued that there is little hard evidence to support this view. Some scholars viewed the entrepreneurial marketing strategy of Small and Medium Enterprises (SMEs) as the process of formulating marketing strategy as easier than in large organization (Kariithi, 2015; OECD, 2017). In a small business, the owner manager can embark on a new marketing strategy without the hassle of consultation and communication. In this regard, there are models that expatiate on marketing effect on business performance.

Simpson et al. (2006) propounded a hypothetical deductive model using a matrix that explained the role of marketing and its relevance to business success. The matrix recommends a positive link between the enterprise's financial performance and its approaches to marketing model. However, Sheetal et al. (2012), and Yen and Chew (2011) are of the view that only effective marketing could help SMEs to gain competitive advantage via overwhelming performance and relationship marketing strategy. To this end, Gilmore et al. (2001) postulated that integration of marketing strategies, marketing mix and market intelligence system can benefit SMEs to a large extent but emphasized on networking as an integral instrument of marketing.

In a study conducted by Ogundele (2000) on a group of entrepreneurs in Oyo, Osun and Lagos States who employed marketing strategy for survival and competitiveness the result showed a significant improvement in the growth of SMEs. According to Ogundele et al. (2013), these groups of entrepreneurs were as a result able to survive in an environment that was inhibitive. Some of the marketing strategies included relationship management, total quality management, market segmentation, product adaptation and modification, process improvement, channel cultivation, process improvement, distribution channel and product innovation (Odundele et al., 20013). They are instrumental to SMEs growth at that time and the practise is still prevalent in today's globally competitive market.

Special sales promotions could offer the exposure that the product or service needs to increase sales in new markets to SMEs as their businesses grow (Meredith, Nelson \& Neck, 1991). Sales promotion could be expensive for small businesses, nevertheless, it could give credit to firm products or services. Ogundele et al. (2013) found that the use of direct sales to end-users that is based on convenience is accepted because SMEs are normally operating on the basis of a face - to - face contact with their customers or end-users and they know their needs at an intimate level. This kind of strategy would not be feasible to a relatively bigger SMEs due to the size of their market and number of customers.

Marketing strategies may run counter to the owner's motives of money or friendship, as been speculated at various levels. Small business owner's desire to run what they perceived as a completely ethical business may prohibit certain 
sales approaches and despite evidence of strong local demand and competitive advantage; an entrepreneur or a shop owner may refuse to open for business on Sunday or Friday for personal reasons (Rohra \& Junejo, 2009).

\section{Marketing Strategies and SMEs Growth and Competitiveness}

There are research studies done on the effect of marketing strategies on the growth of SMEs. A study by Gajanayake (2002) on the impact of marketing strategies and behaviour of Small and Medium Enterprises on business growth and the result indicated that marketing strategies have no significant impact on business growth in Sri Lanka. Another study by Trivedi (2013) on marketing strategies of SMEs in India and the findings revealed that SME's have now understood the importance of exploiting several marketing tools like internet platform, digital advertising, mobile applications for customers, customer relationship management and many others. Njanja (2009) surveyed on the effect of management strategies on performance of micro, small and medium enterprises (MSMEs) in Kenya and it was found that the integrated effect of the management strategies and the related factors had a greater impact on the performance of the MSMEs than any individual strategies.

Similarly, Obonyo (2013) conducted a research on marketing strategies adopted by supermarkets for a competitive advantage and the result showed that location was the only marketing strategy that yields greater returns compared to other strategies. Magunga (2010) did a study on the effects of marketing strategies on the performance of insurance companies in Kenya. Also, a study by Kariithi (2015) investigated the effect of marketing strategies on the growth of small and medium business in air travel agencies in Kenya. The study found that promotion, place and process strategies have a high correlation with the growth of SMEs. Ogundele et al. (2013) did a study on SMEs marketing practices in Nigeria and the findings revealed that SMEs are involved in new product development, process development, process adjustment, segmentation, price discrimination, direct distribution, personal selling, sales promotion, relationship marketing, electronic advertisement and other uses of IT, among the marketing practice.

Sheetal et al. (2012) conduct a sample survey on manufacturing SMEs in India, the result showed that SMEs are very weak in terms of marketing strategies. The findings further suggest that there is a strong need for SMEs to focus on price and product differentiation strategy, brand name, distribution channels, e-marketing strategy and market intelligence system. The findings of the study pointed out areas of weakness of SMEs marketing strategies and recommend areas of the crucial need for the SMEs to be competitive. However, it would be difficult for an SME to implement the whole of the strategies at a time due to some peculiar challenges bedevilling the sector. As pointed out by Ogechukwu and Latinwo (2011), problems faced by SMEs when it comes to marketing strategies implementation include the absence of supportive laws, poor infrastructural facilities, lack of constant man-power and development and difficulty of access to financial support.

Review of the few empirical studies has shown that marketing strategy was noted to be an essential tool in SMEs growth and competitiveness as argued by Kariithi (2015), Sheetal et al. (2015), Ogechukwu and Latinwo (2011) and OECD (2017). Even though there are contrary findings on the impact of marketing strategies on SMEs growth, one could still argue that majority of the results are positive. Hence, the proposition of the current authors stands on the need to explore more marketing strategies as one of the drivers of SMEs growth and competitiveness. In spite of all the challenges faced by SMEs, there is need for them to survive because of the economic and social support they are giving to developing countries.

The connection between marketing strategy and SMEs growth and competitiveness became clearer, as an effective marketing strategy could offer the chance for a firm to capture huge customers by delivering high value. That would lead to increase in sales revenue, which would eventually cause a rise in profit and asset expansion. Again, it enables firms to continue to access relevant information that will make them innovate to meet the changing market demands. The assertions of Hallberg (2000) maintained that SMEs must continue to create niche strategies, capitalising on product quality, flexibility and responsiveness to customer's requirements to compete with large scale firms. Therefore, this article's desire of exploring more potential unpopular marketing strategies that will instigate the growth and competitiveness drives of SMEs in developing countries is on course.

\section{Marketing Strategy Options for SMEs}

There are various strategic options that could be useful to SMEs to bridge marketing activities for growth and competitiveness in the developing economies. In this article, quite some options were proposed and argued based on literature that supports our standing on the need for marketing strategy for SMEs. Some of these options include strategic alliance, clustering, franchise, joint venture and electronic commerce or digital marketing.

Strategic alliances are pioneering means for SMEs to market their products and services, home and abroad (Mokhtar, 2013). It is also supported by O'Dwyer, Gilmore and Carson (2011) who have shown that SMEs engagement in strategic alliances for innovative marketing purposes helped them accomplish two diverse effects: it enables them to accomplish different organizational goals and as well assist them to counter prevailing difficulties especially on resource limitations. In the same vein, OECD (2000) buttressed on the need for SMEs to engage in a strategic alliance for exploiting an international market opportunity. 
Nurturing public-private partnerships and small-firm networks and clusters may be the most expeditious path to a dynamic SME sector. Clustering facilitates the exchange of personnel and diffusion of technology and it also creates new possibilities for efficiency gains. Essentially, these local networks and support systems can help SMEs meet the challenges of globalisation. Networking allows SMEs to combine the advantages of smaller scale and greater flexibility with economies of scale and scope in larger markets - regional, national and global (Hellberg, 2000). They can pool resources and share the costs of training, research and marketing. Relative to larger firms, SMEs can better respond to changing market conditions, evolving consumer preferences and shorter product life cycles by customising and differentiating products. New communication tools make it easier for small firms to reach foreign partners (OECD, 2000). Other options available for SMEs for market opportunities in franchising, joint venture and electronic-based commerce (e-commerce).

The advent of Internet-based electronic commerce (e-commerce) provides great prospects to SMEs in the area of customer base expansion, new product markets entry and streamlining their businesses (Hellberg, 2000). Digital technologies enable SMEs to improve market intelligence, reach scale without mass and access global markets, knowledge networks at relatively low cost and enhances their competitiveness (OECD, 2017; Sheetal et al., 2012). Smaller enterprises can use e-commerce to customise products and services, manage supply processes and inventories, and reduce the time between order and delivery. SMEs most often than not embrace technologies and the Internet more sluggishly than in the case of large firms. Many barriers could have been responsible for SMEs e-commerce slow adoption, comprising of poor understanding of the complexity of its operations, inadequate skills and high initial investment needed to build a feasible e-commerce strategy. Also, the trouble of SMEs in building a reputation, creating consumer trust and confidence in their undertakings make them more vulnerable to difficulties related to authentication and certification; data security and confidentiality; and the resolution of commercial disputes (OECD, 2000; 2017). However, some few SMEs overcame some of these challenges and are thriving in e-commerce channels as start-ups and existing ones are migrating to electronic commerce - emphasising what can possibly be accomplished by SMEs buying into it as marketing strategic tool.

\section{Conclusion}

Marketing is perceived as the interface between enterprises and their customers or clients. Thus, marketing strategy is overwhelmingly important for firms, large or small to have one in place. SMEs were found to be weak in their marketing practices, perhaps due to their face-to-face contact with their sizable customers and challenges of finance. In this article several positions on the kinds of strategies used by SMEs and the ones ought to have been crucial were emphasized. Today many emerging concepts have been added to marketing strategy group, like relationship marketing, network marketing, innovative marketing, standardization, adaptation and clustering (Sheetal et al., 2012). Hence, SMEs must leverage on the emerging strategies to grow and be competitive. Strategies such as strategic alliance, clustering, channel cultivation, differentiation and branding could go a long way in growing the enterprise. The SMEs must evolve with the trend of technological development in terms of production, distribution and communication for survival, growth and competitiveness. Such that they will be able to sustainably meet market requirements in terms of quality, quantity, price and timely delivery with respect to changing market situation. It is on this note that the authors of this article are of the view that SMEs must seek more knowledge of marketing if growth and competitiveness is prioritized.

\section{Acknowledgement}

The author would like to thank Dangote Business School, Bayero University Kano for supporting this research work.

\section{References}

[1] Barbu, C. M., Ogarca, R. F. \& Barbu, M .R. C. (2010). Branding in Small Business. http://www.mnmk.ro/documents/2010special/3BarbuOgarca.pdf. Retrieved on 20th November, 2020.

[2] Bettiol, M., Di Maria, E. \& Finotto, V. (2012). Marketing in SMEs: the role of entrepreneurial sense making, International Entrepreneurship and Management Journal, 8(2), 223-248.

[3] Davidsson, P., Steffens, P. \& Fitzsimmons, J. (2009). Growing Profitable or Growing from Profits: Putting the Horse in front of the Cart. Journal of Business Venturing, 24(4), 388-406.

[4] Delmar, F. (2006). Measuring Growth: Methodological Considerations and Empirical Results. Entrepreneurship Growth of Firms, 1, 62-84.

[5] Falciola, J., Jansen, M. \& Rollo, V. (2020). Defining Firm Competitiveness: A Multidimensional Framework. World Development, 129 (104857), 1-21.

[6] Franco, M., de Fátima Santos, M., Ramalho, I. \& Nunes, C. (2014). An exploratory study of entrepreneurial marketing in SMEs: The role of the founder entrepreneur, Journal of Small Business and Enterprise Development, $21(2), 265-283$.

[7] Gajanayake R. (2002). The Impact of Marketing Strategies and Behavior of Small and Medium Enterprises on their Business Growth. Unpublished Masters of Commerce \& Management Studies thesis. Department of Commerce \& Financial Management, University of Kelaniya. 
[8] Gilmore, A., Carson, D. \& Grant, K. (2001). SME Marketing in practice. Marketing Intelligence \& Planning, 19(1), 6-11.

[9] Hallberg, K. (2000). A Market-Oriented Strategy for Small and Medium-Scale Enterprises. International Finance [10] Corporation, Discussion Paper Number 40.

[11] Hammonds, K.H. (2001). Michael Porter's Big Ideas, Fast Company Magazine, March, pag. 150-154.

[12] Hill, J. (2001). A multidimensional study of the key determinants of the effective SME marketing activity: part 2, International Journal of Entrepreneurial Behavior \& Research, 7(6), 211-235.

[13] ILO (2012). Decent work indicators: concepts and definitions, ILO manual - First edition, Department of Statistics, Geneva.

[14] Izverciana, M., Micleaa, S. \& Potraa, S. (2016). Marketing Practices in SMEs. Case Study: Romania vs. Malta. SIM 2015 / 13th International Symposium in Management, Faculty of Management in Production and Transportation, Politehnica University Timisoara, Romania. Procedia - Social and Behavioral Sciences 221, 135 141.

[15] Kariithi, R. (2015). The Influence of Marketing Strategies on Growth of Small and Medium Business in Air Travel Agencies in Nairobi County in Kenya. Unpublished Masters of Science Thesis in Entrepreneurship and Innovation Management, University of Nairobi, Kenya.

[16] Kiviluoto, N., Brannback, M. \& Carsrud, A. (2011). Are Firm Growth and Performance the same or different Concepts? An Analysis of the Dependent and Independent Variables. Entrepreneurship Growth and Development.

[17] Kotler, P. and Keller, K. 1. (2008). Marketing Management (12th revised ed.). Prentice Hall: Singapore.

[18] Magunga (2010). Effects of marketing strategies on the performance of insurance companies in Kenya, Unpublished MBA Thesis, University of Nairobi.

[19] Marcati, A., Guido, G. \& Peluso, A. M. (2008). What is marketing for SME Entrepreneurs? The need to market the Marketing Approach, Proceedings of the 7th annual congress, International Congress Marketing trends, Venice (1719 Jan), pp. 1-24.

[20] Meredith, G.G. Nelson, R.E. and Neck P.A (1991). The Practice of Entrepreneurship, Lagos: University of Lagos Press.

[21] Mokhtar, N. F. (2013). Choice of Business Aims and Strategies by Small Business Enterprises in Developing Countries. International Journal of Business and Social Science, 4(9), 247-255.

[22] Nelson, R. (1996). The sources of economic growth. Harvard University Press.

[23] Njanja. L. (2009) an investigation into management strategies affecting performance of micro, small and medium enterprises (MSMEs) in Kenya, PhD Dissertation on Commerce, university of South Africa.

[24] Obonyo O. (2013). Marketing strategies adopted by supermarkets for competitive edge, A case of Kisii Town Supermarkets, Interdisciplinary journal of contemporary research in business, 4(12), 44-51.

[25] O'Dwyer, M., Gilmore, A. \& Carson, D. (2009). Innovative marketing in SMEs. European Journal of Marketing, 43(1/2), 46-55.

[26] O'Dwyer, M., Gilmore, A., \& Carson, D. (2011). Strategic alliances as an element of innovative marketing in SMEs. Journal of Strategic Marketing, 19(01), 91-104.

[27] Ogechukwu, A. D. \& Latinwo. H. K. (2011). Entrepreneurial Developments and Small Scale Industry Contribution to Nigerian national development- A marketing interface. Information Management and Business Review, 1 (2) 5168.

[28] OECD (2000). Small and Medium-sized Enterprises: Local Strength, Global Reach. Policy Brief. http://www.oecd.org/cfe/leed/1918307.pdf

[29] OECD (2017). Enhancing the Contributions of SMEs in a Global and Digitalised Economy. Meeting of the OECD Council at Ministerial Level Paris, 7-8 June 2017. https://www.oecd.org/mcm/documents/C-MIN-2017-8-EN.pdf accessed 16-07-2020.

[30] Ogundele, O. J. K. (2000). Determinants of Entrepreneurial Emergence Behaviours and Performance in Nigeria, Ph.D. Thesis University of Lagos, Akoka, Lagos.

[31] Ogundele, O. J. K., Akingbade, W. A., Saka, R. O., Elegunde, A. F. \& Aliu, A. A. (2013). Marketing Practice of Small and Medium Enterprises (SMEs): Perspective from a Developing Country. Mediterranean Journal of Social Sciences, 4(3), 243-258.

[32] Putnik, G. D. \& Cruz-Cunha, M. M. (2008). Encyclopaedia of Networked and Virtual Organisations (vol.3). IGI Global Publisher of timely Knowledge. Doi: 10.4018/978-1-59904-885-7.

[33] Rohra, C. L. \& Junejo, M. A. (2009). Strategies for Developing the Success of Small Medium Enterprises in Pakistan. International Journal of Business Management, 4(6), 171-175.

[34] Sarlija, N., Pfiefer, S., Jeger, M. \& Bilandzic, A. (2016). Measuring Enterprise Growth: Pitfals and Implications. International Journal of Social, Behavioural, Educational, Economic, Business and Industrial Engineering, 10(6), 1781-1788.

[35] Sheetal, Sangeeta \& Kumar, R. (2012). Marketing Strategies of Small and Medium Enterprises: A Sample Survey. IJMRS's International Journal of Management Sciences, 1(02), 60-71. 
[36] Simpson, M., Padmore, J., Taylor, N. \& Frecknall-Hughes, J. (2006). Marketing in small and medium sized enterprises. International Journal of Entrepreneurial Behaviour \& Research, 12(6), 361-387.

[37] Tarassova, T. (2003). Strategy for a Small Enterprise: Literature Review. Management Decision, 27(7), 67-88.

[38] Trivedi J. (2013). Marketing strategies of Small and Medium sized Enterprises. Research Journal of Management Sciences, 2(8), 20-22.

[39] Vlachevi, A., Notta, O. \& Tsounis, N. (2017). Factors Affecting Firm Competitiveness and Performance in the Modern Business World. IGI Global Publisher of timely Knowledge. Doi: 10.4018/978-1-5225-0843-4.

[40] Wiig, K. M. (2004). People-Focused Knowledge Management. Burlington, MA: Elsevier Butterworth-Heinemann. 